\section{Brian Ford}

\author{
Practice address \\ WSP Environmental \\ Buchanan House \\ 24-30 Holborn \\ London $\mathrm{EC}_{1} \mathrm{~N}_{2} \mathrm{HS}$ \\ United Kingdom \\ Brian.Ford@WSPGroup.com
}

\section{Passive downdraught evaporative cooling: principles and practice}

\author{
Air conditioning is now recognized as a significant factor in global \\ warming and climate change. In the search for alternatives, passive \\ downdraught evaporative cooling (PDEC) is proving to be both \\ technically and economically viable in different parts of the world. \\ Brian Ford describes the principles and current practice of this \\ innovative approach to cooling in the hot dry regions of the world.
}

Buildings globally are responsible for about $40 \%$ of all energy consumption. In the US, air conditioning (a.c.) alone consumes approximately $16 \%$ of all electricity, but is responsible for $43 \%$ of the peak load (Hawken and Lovins, 1997). The demand for air conditioning is a major reason for current supply problems on the west coast of the US, $\mathrm{CO}_{2}$ emissions from air conditioning world-wide make a significant contribution to greenhouse gas emissions; but air conditioning also uses refrigerants, and commonly used refrigerants (such as R134a and R22) are between 1300 and 1700 times more potent per molecule than $\mathrm{CO}_{2}$ in contributing to global warming.

The stratospheric ozone layer is the world's UV radiation shield. UV affects photosynthesis and kills phytoplankton (the basis of oceanic food chains). Refrigerants (both CFCs and HCFCs) are responsible for the 'holes' appearing in the ozone layer. CFCs are extremely stable and (in spite of the Montreal Protocol) are still being manufactured in China and India. The black market for CFCs in the US is said to rival that for narcotics. HFCs continue to be used, of course, throughout the world, although the search for less damaging alternatives is bearing fruit. Alternative refrigerants may be part of the answer, but there is now strong interest in more radical alternatives to air conditioning.

Last year the Carrier Corporation and Toshiba sold over US $\$ 8$ billion worth of air-conditioning equipment worldwide. They are the major players in a market that continues to expand. Expanding demand for a.c. is a major driver for new central generating plant (power stations) because of its impact on peak load demand, and of course this in turn leads to greater demand for fossil fuels. These characteristics are common throughout the world, and many countries (including Japan \& the US) are finding it hard to construct new generating capacity fast enough to keep up with the increase in demand.

The Carrier Corporation has realized that the owners and occupiers of buildings don't necessarily want air conditioning per se, they want thermal comfort (Hawken and Lovins, 1997), and they have now started to offer 'coolth services', and to advise customers on how they can reduce their cooling requirements. While this is welcome, expanding global sales of cooling equipment underline the continuing negative impact of this technology on the environment, and the need for more radical alternatives.

\section{Cooling without air conditioning.}

The tradition of 'cooling without air conditioning', which incorporates a range of design responses to climate apart from evaporative cooling, has its origins in ancient Egypt; it subsequently spread eastwards through the Middle East and Iran to north India with the Moghul empire, and westwards across north Africa to southern Spain.

In the Middle East there is a long tradition of using various techniques to encourage evaporative cooling both within and between buildings. Bahadoori describes cooling systems in Iran (incorporating wind-catchers, porous water pots and salsabil) which have been effective for several centuries (Bahadoori, 1978). In this tradition, wind-catchers guide outside 


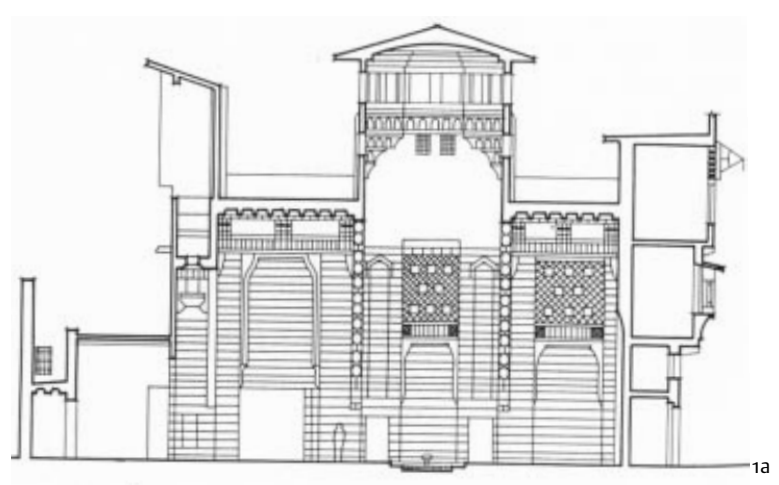

air over water-filled porous pots, inducing evaporation and bringing about a significant drop in temperature before the air enters the interior [Figs. $1 \mathrm{a}$ and $\mathrm{b}]$. More recently, this tradition has been taken up by Hassan Fathy and others, and developed for cooling schools and other buildings. Often, the air flow rate is enhanced by catching and redirecting the prevailing wind. Fathy comments on design strategies to exploit these effects not only within buildings but in external spaces as well (Fathy, 1986).

In north India, the Moghul palaces and gardens exploited evaporative cooling to delight the eye and other senses as well as providing thermal relief. Thin water chutes (salsabil) and other evaporative cooling techniques were features of Moghul architecture from the thirteenth to the seventeenth centuries [Fig. 2]. The intense dry heat and dust of the summer in north India calls for the creation of an internal 'refuge' or haven from the extremes of the external world. The diurnal swing in temperature is 'dampened' by the mass of stone and earth, and the air is further cooled by the evaporation of water in the ventilation air flow path. This is exemplified perfectly in the beautifully atmospheric 'Rai Pravina Mahal' in Orchaa (Ford and Hewitt, 1996) [Figs. 3a and $\mathrm{b}]$.

The geographical spread of this tradition from north India to southern Spain is remarkable. The Moorish Islamic tradition in southern Spain incorporates extremely subtle design strategies, which must have developed empirically, to moderate conditions both inside and outside buildings. A midsummer visit to the 'Casa de Pilatos' in Seville [Fig. 4a] provides an experience of what can be achieved. A central paved courtyard, searingly hot in the middle of the day, is surrounded by narrow section buildings that are linked by large openings to green garden courts beyond. Heat rising from the paved central court pulls cooler humidified air from the shaded garden courts across the narrow rooms, where the occupants appreciate both the lower temperatures and the air movement.

Many aspects of the tradition outlined above were reviewed by the designers of the Expo site in Seville for the 1992 World Fair (Alvarez, 1991). This included the $30 \mathrm{~m}$ high 'cool towers' of the Avenue of Europe, which employed high-pressure water misting nozzles (micronizers) to induce downdraught

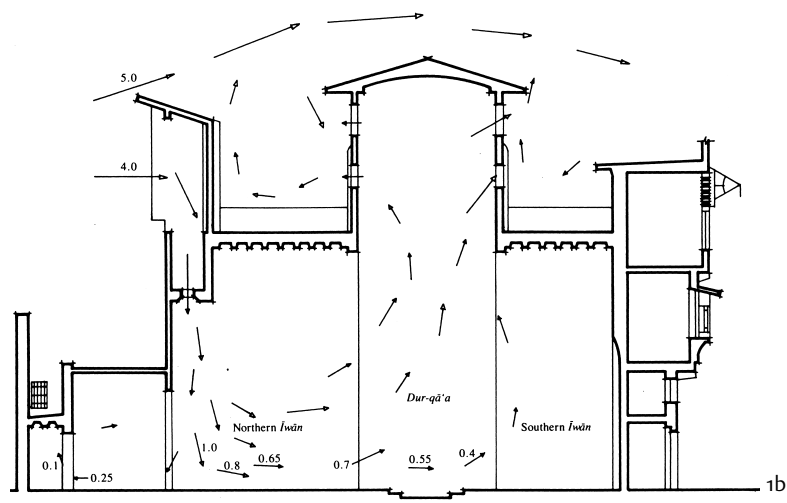

cooling [Fig. 4b]. This technique of passive downdraught evaporative cooling (PDEC) has only recently been applied to buildings, but has enormous potential to displace the need for conventional air conditioning.

\section{What is PDEC?}

In the twentieth century, evaporative cooling was applied in buildings throughout the world in conjunction with a mechanically driven air supply (known widely as 'Desert' coolers). Recently, attention has returned to the potential of exploiting the benefits of direct evaporative cooling while avoiding mechanical assistance by using buoyancy or wind forces to drive the air flow.

When water evaporates within a stream of ambient (outside) air, the temperature of the air is lowered and its moisture content is elevated, while its 'wet bulb' temperature remains constant. The cooling of the air is also reflected in an increase in density, sufficient to drive a downdraught of air through a building. In the late 1980 , a number of successful experiments were undertaken which tested the evaporation of water within a downdraught tower, hence the term Passive Downdraught Evaporative Cooling (PDEC).

The cooling effect of a PDEC tower is the product of the temperature drop and the volumetric air flow rate. The principal factors that influence performance are therefore the characteristics of the climate (ambient dry bulb and wet bulb temperatures), the height of the tower and the crosssectional area of the air inlets (including their resistance to air flow). As a result of the potentially high air-flow rates generated by a PDEC system, the internal air and surface temperatures are governed mainly by the temperature of the cooled air, and the level of internal heat gains. Indoor air temperatures in a well insulated building may be only 1 to $2^{\circ} \mathrm{C}$ above the temperature of the air exiting from the evaporative cooler. The high air movement and low air and surface temperatures can yield significant improvements in thermal comfort conditions, and significant reductions in energy demands compared with equivalent air-conditioned buildings.

\section{Contemporary applications}

In an experimental building in Tucson, Arizona in 


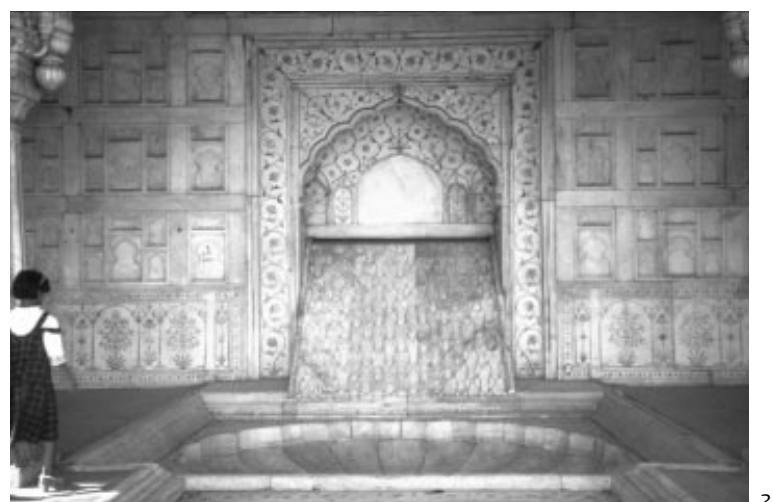

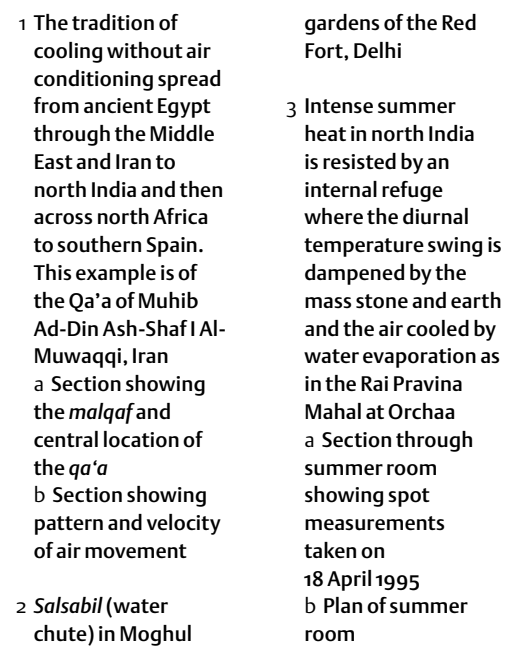
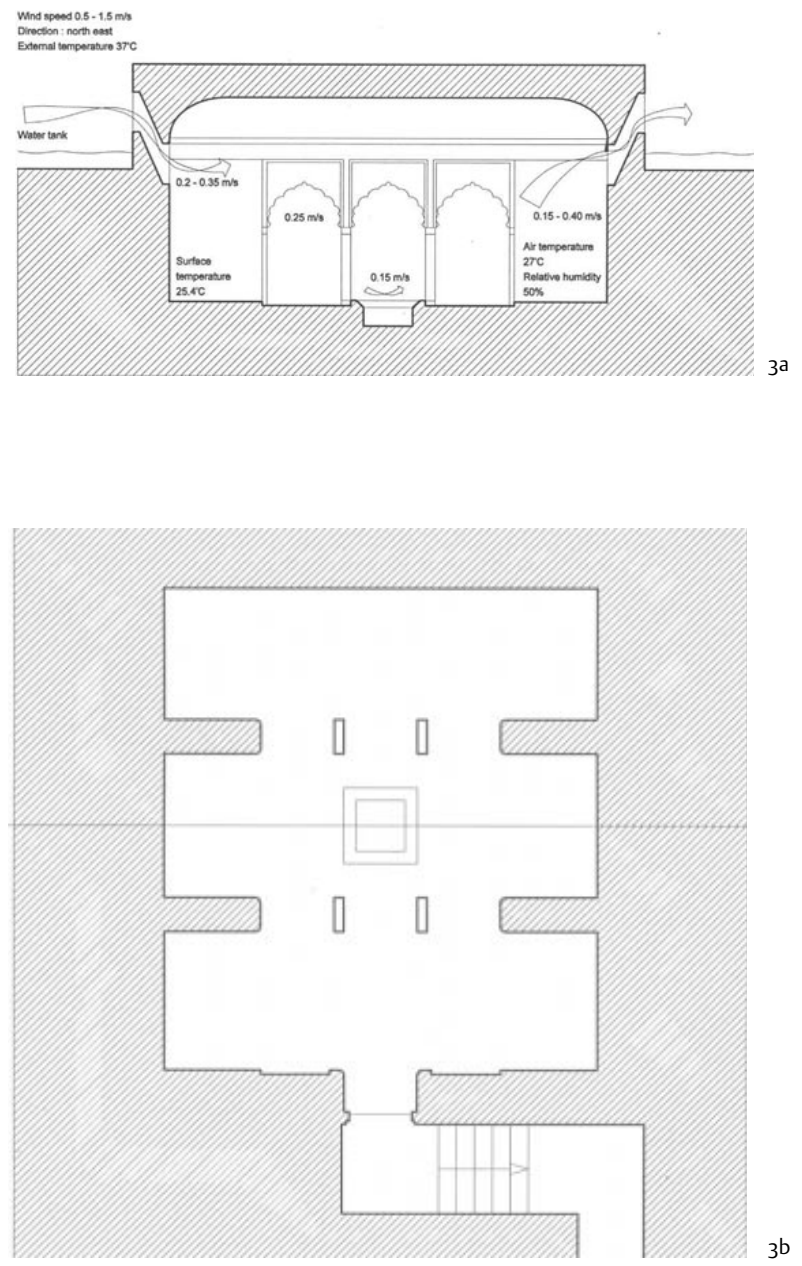

1986 (Cunningham and Thompson, 1989), a downdraught tower incorporating wetted cellulose pads demonstrated the effectiveness of direct evaporative cooling in driving a substantial air flow through the building [Figs. 5a and b]. Givoni, in analyzing the test data, confirmed the effectiveness of this strategy (Givoni, 1990). From a sample of the published results it is interesting to note that the exit air temperature from the cooling tower was measured at $24^{\circ} \mathrm{C}$ when the outdoor dry bulb temperature (DBT) reached $41^{\circ} \mathrm{C}$ and the wet bulb temperature (WBT) was $22^{\circ} \mathrm{C}$. The large drop in temperature through the cooling tower, coupled with high air change rates (in this case believed to be induced by buoyancy alone), indicates not only the significant cooling potential of this technique, but also that it drives the ventilation air through the building. Since this experimental work, a number of small buildings in Arizona have been designed incorporating cool towers with wetted cellulose pads.

Cunningham and Thompson's experiments demonstrated that buoyancy forces alone can achieve very high air change rates (30 air changes/hour were recorded in their experimental building). This is significant if applied to a building, because fans normally required to drive air around the building can be avoided. Fan power can represent $30-40 \%$ of the electrical energy required by a
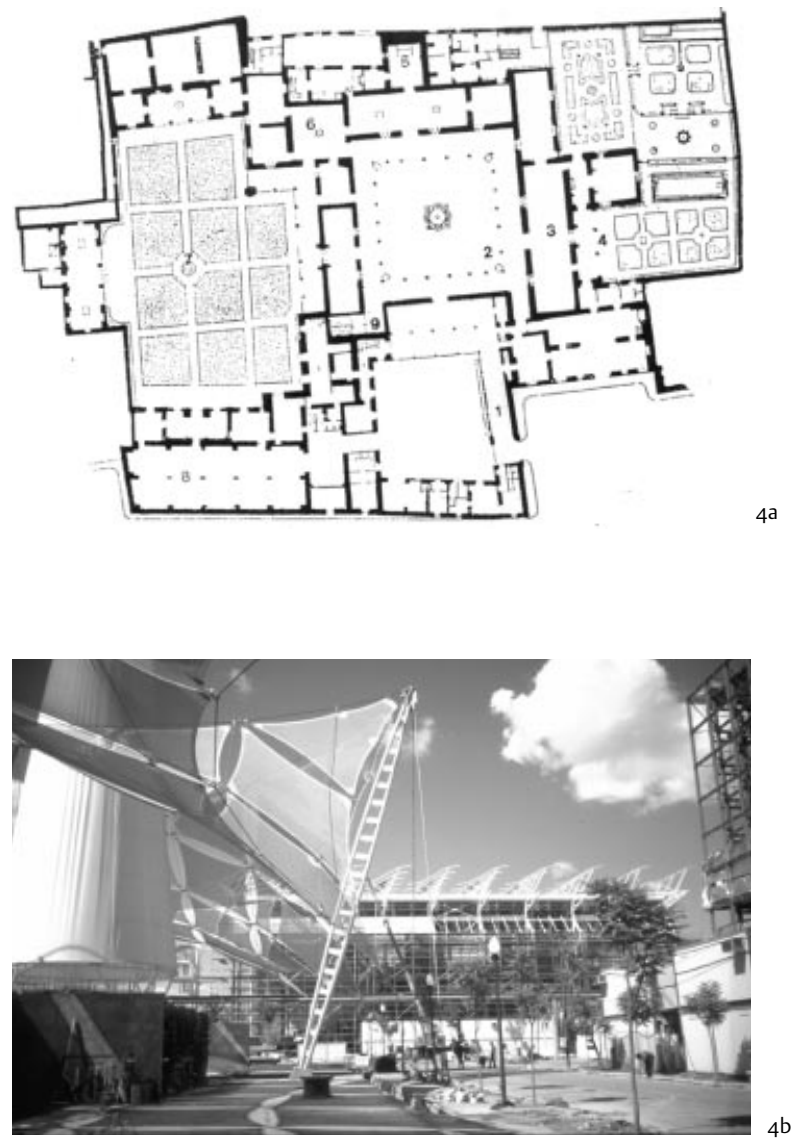


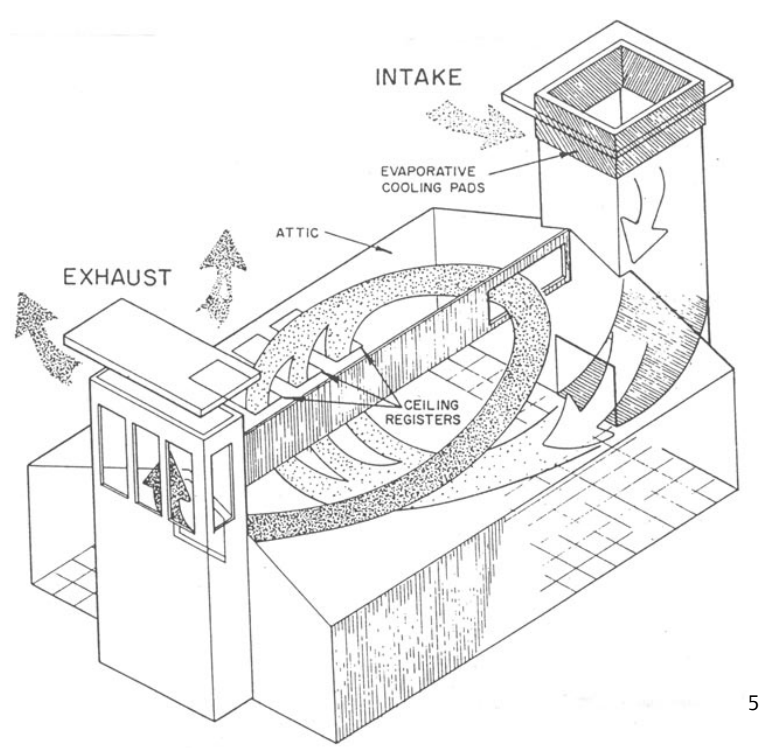

$5 a$

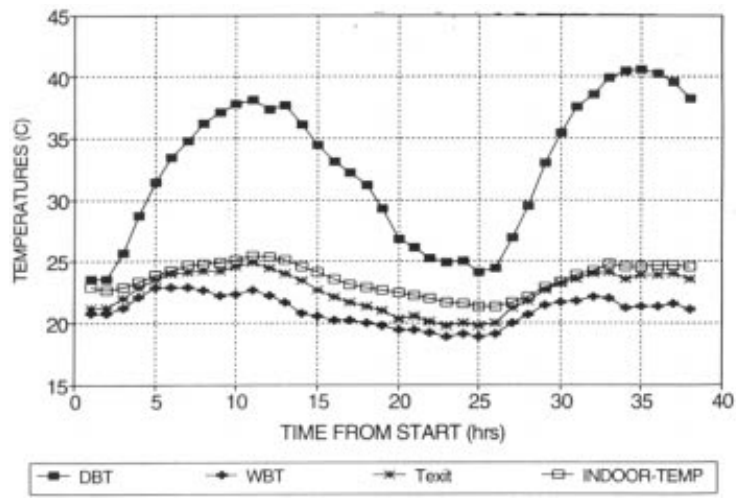

$\begin{array}{ll}5 \text { An experimental } & \text { a Sketch view of } \\ \text { building with a cool } & \text { experimental building } \\ \text { tower in Tucson, } & \text { to show pattern of air } \\ \text { Arizona in 1986 } & \text { movement } \\ \text { demonstrated the } & \text { b Measured data } \\ \text { effectiveness of } & \text { from experimental } \\ \text { direct evaporative } & \text { building by } \\ \text { cooling in driving air } & \text { Cunningham and } \\ \text { flow } & \text { Thompson }\end{array}$

conventionally air-conditioned building. The innovation in relation to contemporary buildings is therefore not the use of evaporative cooling per se, but rather the rediscovery that it can drive the air flow through the building. Typically, in a new airconditioned office building in southern Europe this might represent a saving of $7 \mathrm{o}^{-}-8 \mathrm{okWh} / \mathrm{m} 2$ per year $\left(35^{-} 45 \mathrm{~kg} / \mathrm{m} 2\right.$ per year).

The first large-scale application of PDEC was in the Torrent Research Centre in Ahmedabad [Figs. 6a-c]. Designed by Abhikram Architects and completed in 1998, this project demonstrated that this approach to cooling could be applied to a large, complex laboratory building (Ford et al, 1998). The brief required over $17, \mathrm{ooom}^{2}$ of pharmaceutical research laboratories, including 'unclean' areas like chemical synthesis laboratories, and 'very clean' areas like tissue culture, molecular biology and drug design areas. Conventional wisdom would suggest that over $50 \%$ of such a new laboratory building would require refrigerant-based air conditioning, in order to meet the environmental requirements within the laboratories.

Typically, laboratories and offices are arranged on three levels either side of an open concourse, which allows the circulation of people between spaces [see Fig. $6 \mathrm{~b}$ and c]. This arrangement allows evaporatively cooled air to be introduced to the occupied spaces at each level, and exhausted via perimeter stacks. In this way, the working areas are both physically and thermally buffered from the external environment.

Measurements of air temperature and relative humidity in different parts of the building in April 1998 revealed that very significant cooling and high air change rates were achieved. Peak temperatures of $27^{\circ} \mathrm{C}$ in the ground floor laboratory, and $29^{\circ} \mathrm{C}$ at first floor, were achieved when the external maximum reached $38^{\circ} \mathrm{C}$. Over the same period, air change rates of 9 per hour on the ground floor and 6 per hour at first floor were recorded. The staff reported that during the summer (February - June) the laboratories are comfortable without fans and are not stuffy or smelly, as most chemistry labs are, even when air conditioned. During the monsoon (July September), the evaporative cooling system is not operated, of course, so ceiling fans are used to enhance comfort for these two to three months.

In the first year since its occupation, the Torrent Research Centre was reported to have used approximately $64 \%$ less electrical energy than the equivalent conventionally air-conditioned building. Expenditure on M\&E plant was reduced by $36 \%$, which also provides further savings in maintenance costs.

\section{The wider context}

Of course the context of both construction and energy use is very different in India compared with Europe or the US. In India, construction costs are generally approximately one tenth of costs in Europe, while energy costs are relatively much higher. This situation is compounded by the fact that energy supply in India is unreliable, so major businesses very often invest in expensive diesel generators to guarantee their supply. This all adds up to a major incentive to reduce the base load electricity requirement. Recent power shortages and price rises in California, are having a similar effect there, although the reaction of the Bush administration has been to encourage further exploitation of fossil fuel reserves, rather than address the demand side of the equation and promote energy efficiency.

It has been argued (Hawken and Lovins, 1998) that improvements in 'resource efficiency' can result in a simultaneous increase in market value (of cooling for example) and reduction in non-renewable resource consumption. Just as BP are announcing that they have gone 'Beyond Petroleum', companies like Carrier may embrace 'Cooling without Air Conditioning'. This may sound far-fetched, but its potential is reflected in the considerable research effort into the new market for PDEC in Europe, as well as signs of real change in the US. 


\section{PDEC for a speculative office in Seville}

Design studies for a speculative office building in Seville in southern Spain (completed as part of a recent $\mathrm{EC}$ funded research project) resulted in a building which met the British Council of Offices (BCO) criteria, providing both open-plan and cellular office space without compromising the PDEC system. (Similar design studies for a site in Catania, Sicily, by Mario Cucinella Architects were also part of the EC research project.)

The proposed office building in Seville deals simultaneously with the commercial requirements of the brief, the constraints of the urban site and geometrical implications of the PDEC strategy. The design attempts to achieve an essentially 'deep plan' office floor plate (overall width $27 \mathrm{~m}$ ) incorporating substantial (6m wide) light wells, which also serve as the 'transitional space' through which evaporatively cooled air is distributed to each floor [Figs. $7 \mathrm{a}-\mathrm{g}$ ]. The open shafts in the centre of the building are surrounded by open-plan offices, with cellular offices and meeting rooms around the perimeter.

Offices on the south (street) side of the building are protected from noise and pollution by exhausting air via perimeter shafts which allow stale air to either fall (in still air conditions) or rise (in windy conditions). Since the prevailing wind is also from the south-west, this approach avoids the potential problem of positive pressure on exhaust air vents. Exhaust air from open-plan offices passes through a bulkhead duct located in the perimeter cellular offices, and out via automatically controlled top hung ventilators into the perimeter shaft. These shafts, expressed fully in the Torrent building, are deliberately suppressed in the Seville office building, terminating in a relatively low continuous parapet.

The performance of the final design was evaluated in great detail in terms of both cost (by the Davis Langdon Consultancy) and thermal performance. Performance analysis undertaken at De Montfort University (Lomas, 1999) revealed that while PDEC can achieve satisfactory conditions for $85 \%$ of the time, the wet bulb temperature is sometimes too high in Seville to rely on PDEC for cooling. Mixed mode operation is therefore proposed for this office building to maintain internal air temperatures below $26^{\circ} \mathrm{C}$. Nevertheless, simulation results indicate energy consumption approximately $75 \%$ below that required for the air-conditioned reference building.

The cost analysis revealed that the PDEC building could be built for $6 \%$ less than the equivalent air-conditioned building. This is extremely significant for the wider take-up of this approach. Not only are air-handling units, ductwork, suspended ceilings and related controls avoided, but also building fabric savings can be achieved because floor to floor heights can be reduced. It is a popular misconception that environmental responsibility in architecture inevitably results in higher costs. The Seville office building demonstrates that there can also be significant capital cost savings as well as the revenue benefits of reduced maintenance and energy costs, associated with adopting PDEC.

The Seville project also addresses the problems of
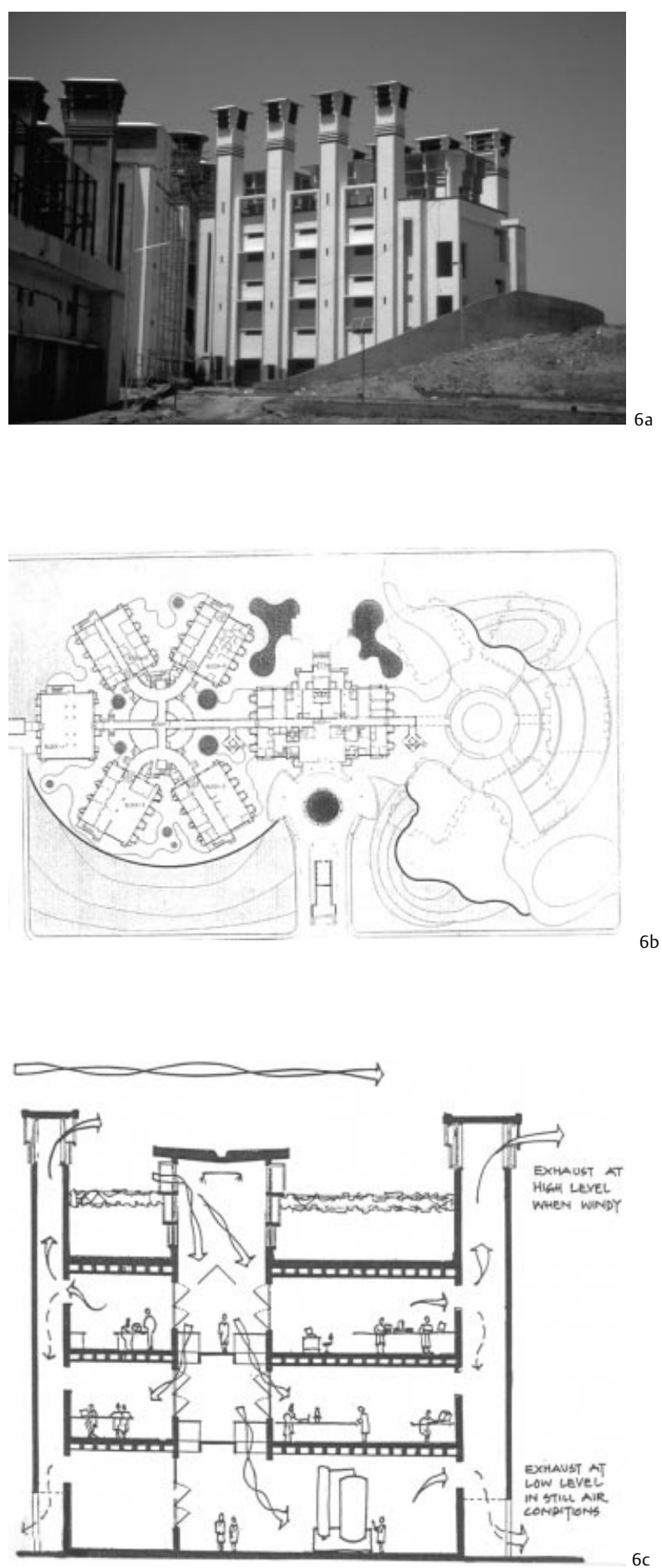

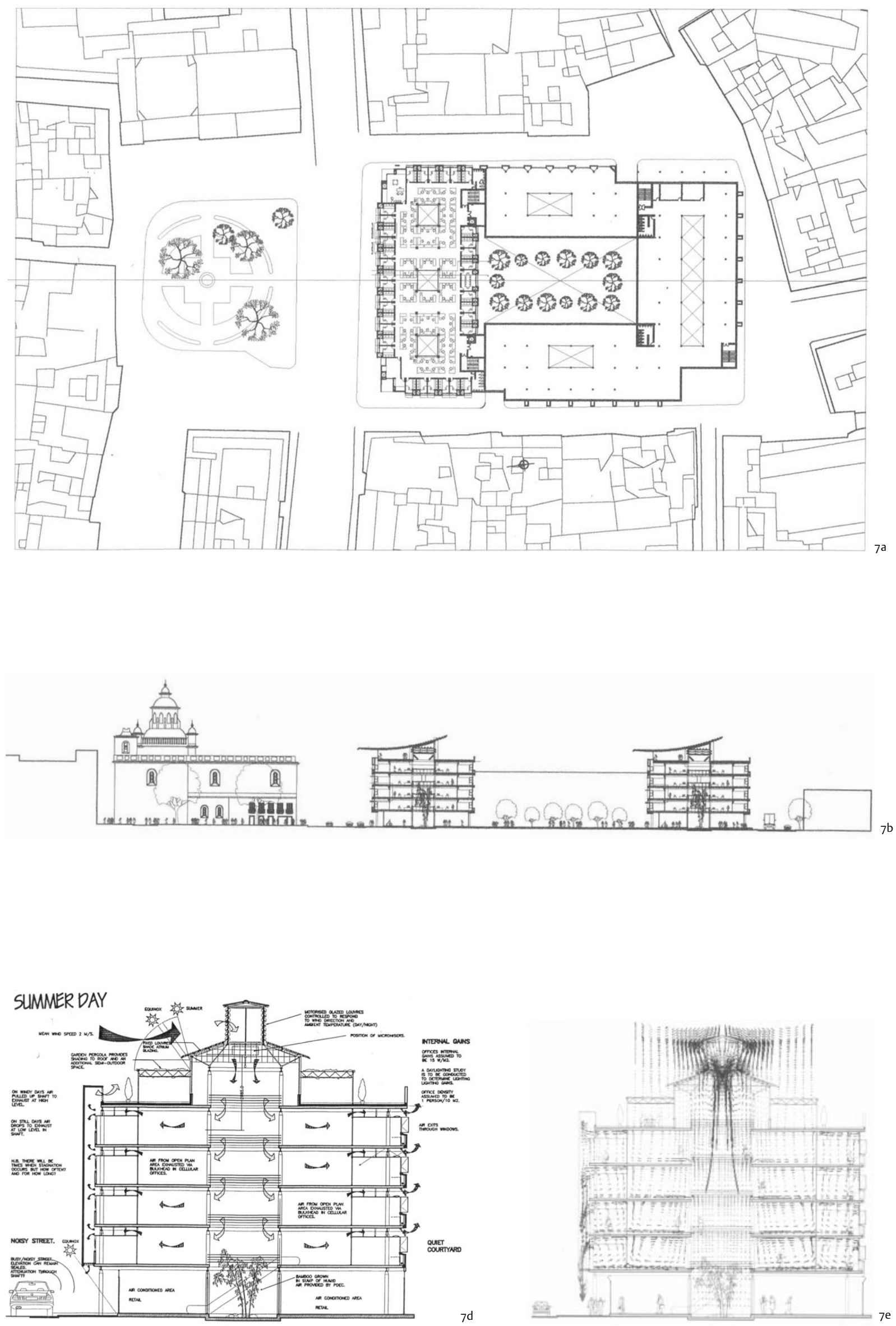


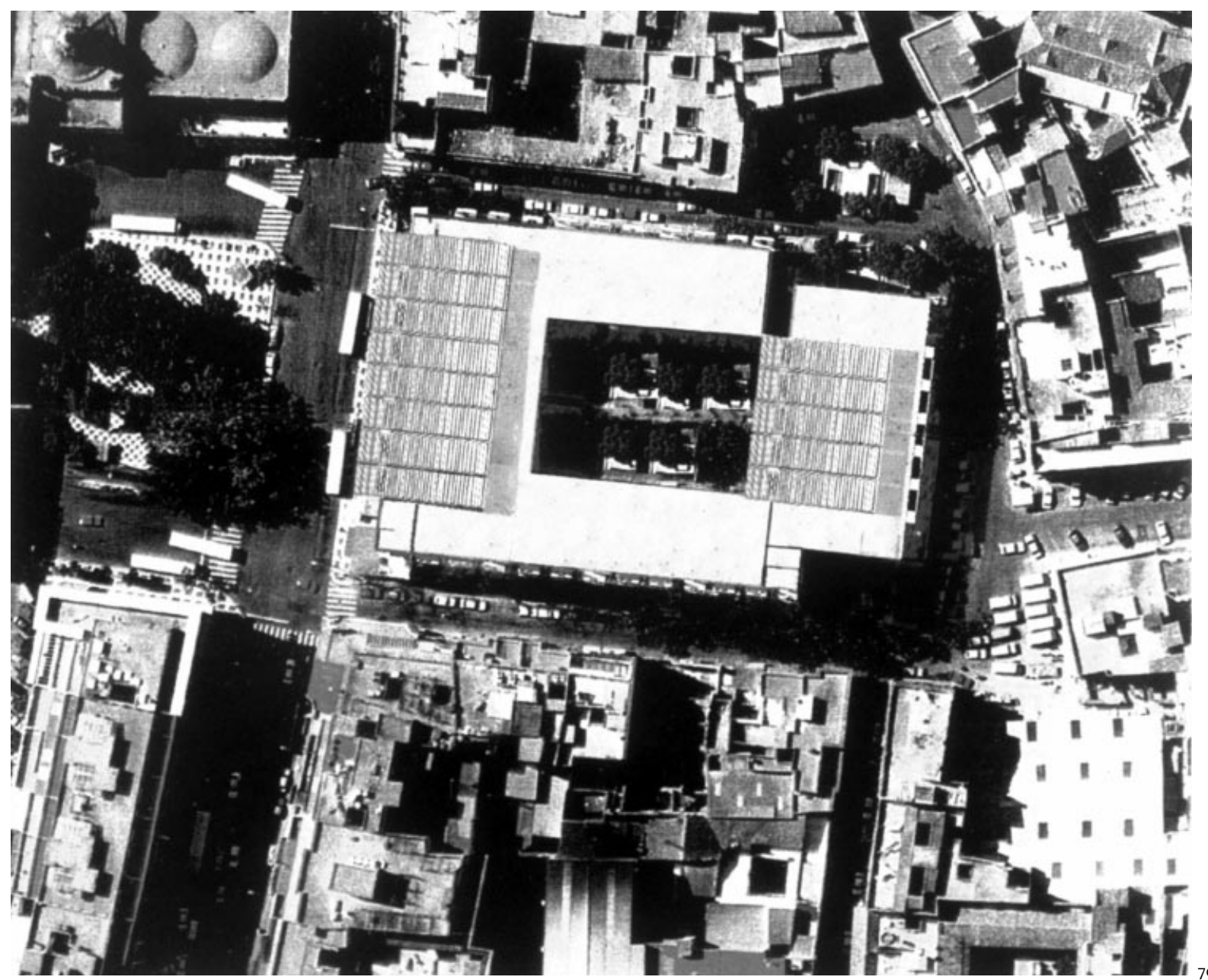

$\begin{array}{ll}\text { 7 Design studies for a } & \text { section showing } \\ \text { speculative office } & \text { PDEC ventilation } \\ \text { building in Seville } & \text { strategy, } \\ \text { provides both open- } & \text { preliminary } \\ \text { plan and cellular } & \text { proposal } \\ \text { offices without } & \text { e Section with CFD } \\ \text { compromising the } & \text { plot of air velocity } \\ \text { PDEC system } & \text { vectors, De } \\ \text { a Site plan } & \text { Montfort University } \\ \text { b Site section } & \text { f Section, final } \\ \text { c Aerial } & \text { proposal } \\ \text { photomontage } & \text { g Model 'slice' of } \\ \text { d Diagramatic } & \text { final proposal }\end{array}$
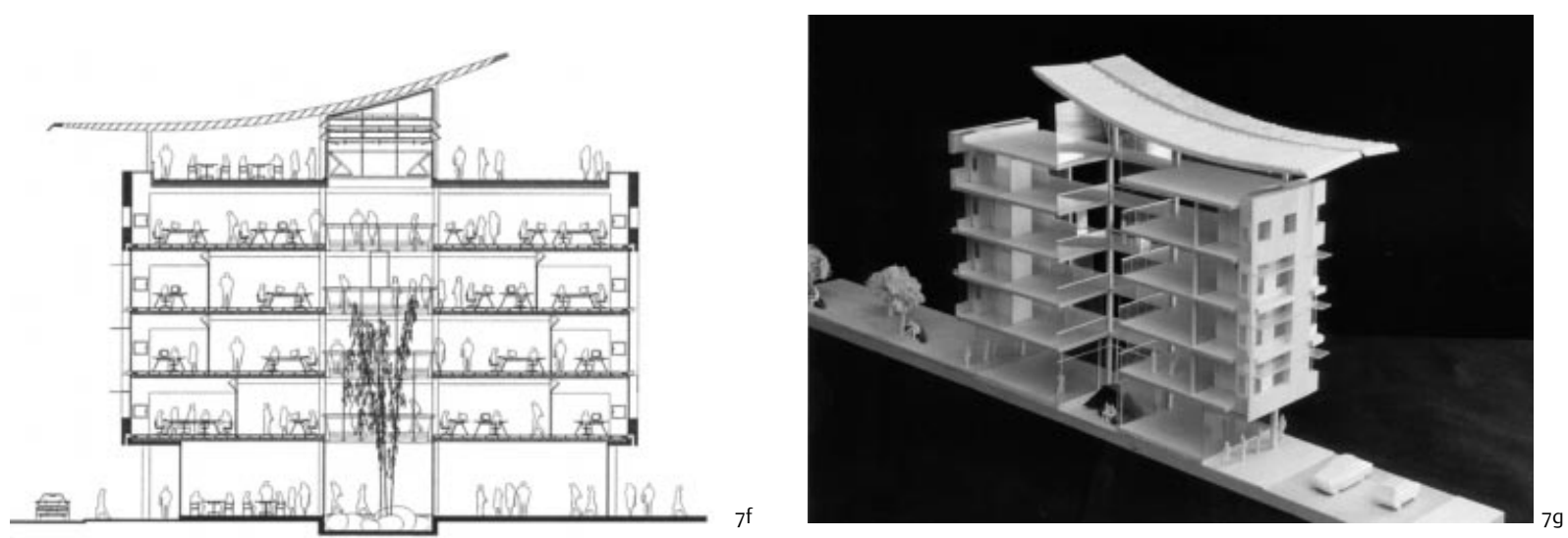
Typical peak daily external

air temp. $=32^{\circ} \mathrm{C}$

(January Mean Max $=32 \mathrm{C}$ )

Relative humidity $=30 \%$

C)

SUPPLY AIR at high level

Exposed faceted

concrete soffit

provides low mean

radiant temp.

(Typically $24 \mathrm{C}$

in summer)

Micromisers within top

of bell-mouth cool tubes

mist water to induce passive

downdraught evaporative

cooling (P.D.E.C.)

EXHAUST AIR at low level

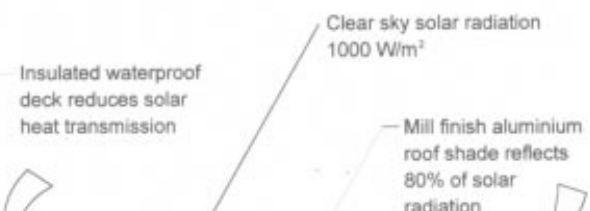

87

Midday Dec

22nd

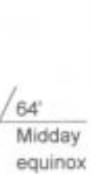

Midday
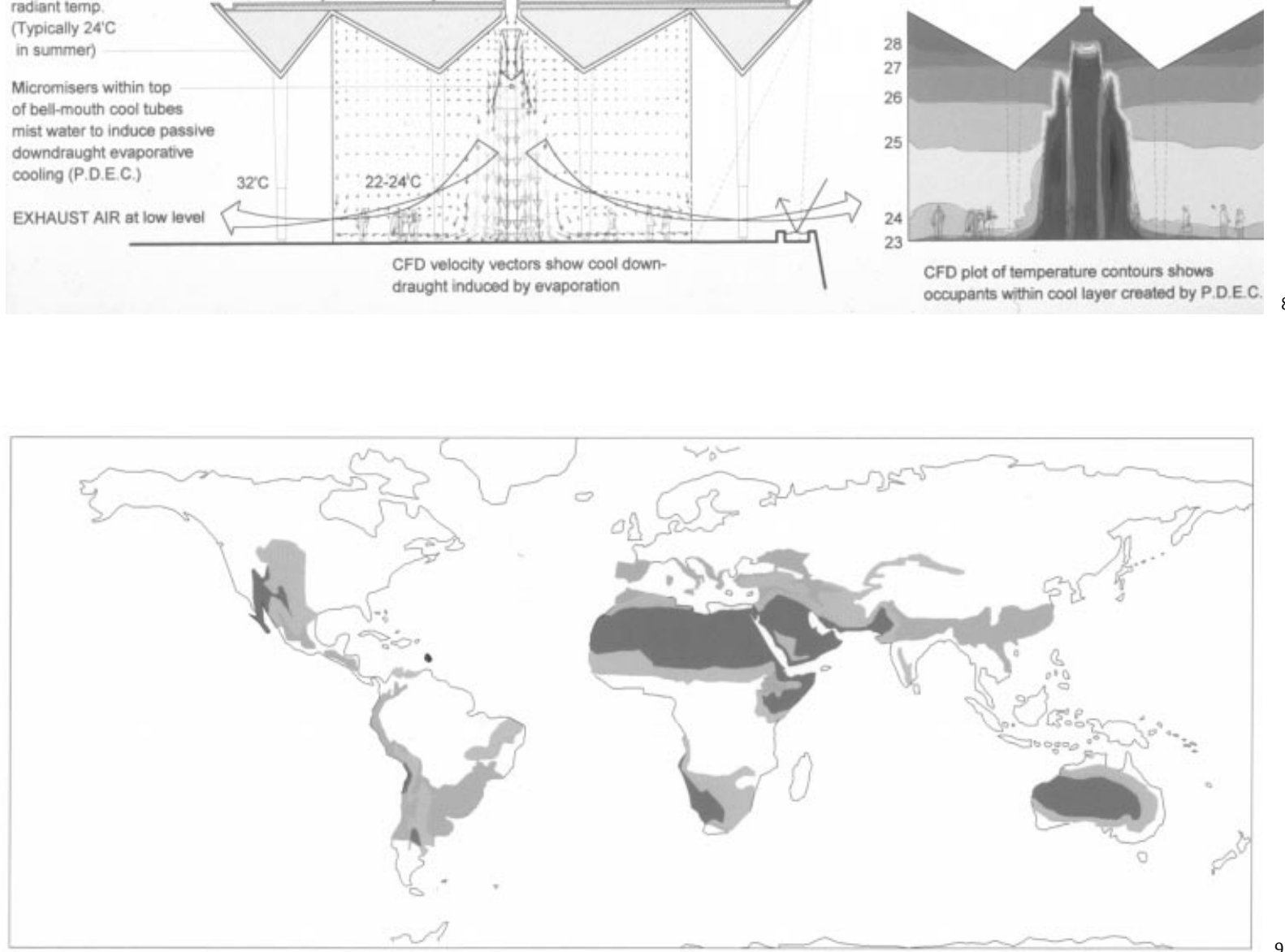

Classification of climate zones where PDEC is applicable

III stoppe

En Temperate

Doser

8 Application of PDEC
to a large public
space: diagram of
cooling strategy
submitted as part of
the International
Competition for the
new Constitutional
Court,
Johannesburg, South
Africa
9 Map of the world
showing the
geographic
applicability of PDEC

applicability of PDEC city centre noise and air pollution [Figs. $7 \mathrm{e}^{-\mathrm{g}}$ ]. The facades of the building are sealed, buffering the office interior from the noise and pollution of the busy commercial street on its south side. Air is introduced to the building at high level, where the concentration of pollutants is significantly lower than at street level. It then enters the separate office floors via light well and vent shafts. Balancing the air volume flow rate at each level is achieved by reducing the open area (and therefore resistance) progressively down the building. The design allows for perimeter cellular offices as well as central openplan areas, allowing flexibility in office layouts as occupancy changes.

Mixed-mode downdraught cooling systems.

The research project also investigated the wider application of this technique within southern 
Europe, generating maps of applicability related to the governing criterion of wet bulb temperature. These maps indicate that while PDEC may be applicable in much of southern Europe, it is rarely applicable for $100 \%$ of the time (simply because at times the wet bulb temperature is too high). Therefore, some form of back-up cooling may be required, depending on location, building type, and internal heat gains. Clearly the back-up system cannot be a conventional a.c. system as this would imply a duplication of costs.

A back-up system that mimics the downdraught operation of PDEC (i.e. no fans) is required. Engineers suggested that chilled water cooling coils, located high in the supply air shafts, could perform this role. While requiring chilling equipment, the use of cooling coils has many of the advantages of the PDEC system (i.e. avoids the need for air-handling units, ductwork, suspended ceilings and so on).

The combination of PDEC and cooling coils to provide downdraught cooling under both dry and more humid conditions, has been included in the design for the new Stock Exchange in Malta by architects Architecture Project. This project involves the refurbishment of an eighteenth-century church to provide office accommodation on three levels around a central atrium. In dry conditions, air will be supplied at high level via ridge vents, and micronizers will induce downdraught cooling, driving air through the atrium and exhausting at low level. In more humid conditions, the ridge vents are closed, and downdraught cooling is induced by cooling coils located just below the ridge. Performance simulation indicates that PDEC will operate for about $25 \%$ of the summer period in Malta, and the cooling coils will cut in when the internal relative humidity exceeds an agreed threshold.

\section{Risks and remedies}

So far, this review has concentrated on the benefits of PDEC. However, there are a number of associated technical problems and disadvantages. Hardness of the water is significant in terms of the potential build-up of scale, and therefore water quality has to be good otherwise nozzles will block. High pressures (>4oBar) are required to minimize water droplet size and maximize evaporation, which implies more expensive pumps and plumbing. The risk of microbiological contamination of the water supply to the misting nozzles must also be minimized. This can be addressed by a combination of design measures (including the use of UV filters in the supply line to the micronizers), regular maintenance, and testing, but it would clearly be better if this was not an issue.

In many parts of the world the potential disadvantages of using micronizers (risks of microbiological contamination, blockage of micronizers, high-pressure stainless-steel plumbing fittings etc.), are a powerful disincentive. 'Low-Tech' solutions may be more appropriate in locations where water quality is poor, or where high-pressure plumbing is unfamiliar. The practical integration of such systems within the building envelope is fundamental to the feasibility of this approach. If simpler techniques currently under investigation do prove technically and financially viable, the market potential could be significant.

\section{The market potential for PDEC in southern Europe}

An investigation (under the EC Altener programme) of the market potential for PDEC within southern Europe, has recently started. Data on the building stock in different countries will be reviewed in the context of the technical constraints of PDEC to establish a model of applicability. This research will help those involved with the procurement of new buildings and the refurbishment of existing buildings, to assess the potential strategic value of PDEC to their investment decisions. A preliminary assessment within Spain and Italy suggests that the market for new office and commercial buildings could benefit by capital cost savings of 40 million Euro/year, and energy cost savings of $8.4 \mathrm{~m}$ Euro/year, if there is a $10 \%$ take up of PDEC. If such savings can be achieved in $10 \%$ of all new non-domestic buildings in Spain and Italy, capital cost savings could amount to over 2 billion Euro/year. Such savings are a powerful incentive to the take up of PDEC in southern Europe.

\section{The market for PDEC in the US}

With the current attitude of the Bush administration to energy use, PDEC would seem unlikely to find a market in the US. However, the news that adiabatic cooling has been applied in the new law court building by Richard Meier in Phoenix, Arizona (Meier R., 2001) is very encouraging. It demonstrates confidence in the approach, both in terms of being a viable passive cooling technique in hot dry climates and in being able to resolve the potential risks and disadvantages.

The courtrooms and administrative offices are arranged on six levels, and are accessed via a huge $(107 \times 46 \mathrm{~m})$ atrium which runs the full length of the building. The atrium is a glass box, intended to represent the 'transparency' of the judicial process, and to a provide the major public space in the building. At first sight, this solution seems questionable, even crazy, given its desert location. However, the extensive use of shading and the application of passive evaporative cooling, have enabled the designers to achieve comfort conditions for most of the year, without the use of mechanical conditioning.

The cooling and ventilation of the space is driven by the evaporation of a water 'mist' into a stream of ambient air drawn in via openings at high level. As the moisture is absorbed, the temperature drops and the air becomes denser, descending to the floor of the atrium. Performance predictions indicate that temperatures at floor level will not be greater than $25^{\circ} \mathrm{C}$ for most of the year. Some benefit is obtained from 'spill-air' from the air-conditioned courtrooms and offices, which escapes into the atrium from the balconies.

The application of PDEC to a large public space attached to courtrooms was proposed in a 
competition entry for the New Constitutional Court in Johannesburg (Weston and Ford, 1998). This (unbuilt) proposal illustrates the potential opportunities for PDEC to be applied to very large public spaces [Fig. 8], suggesting potential future application to transport interchanges, sports venues, shopping malls and concert halls.

The projects described in this paper illustrate the range of building types and climatic regions in which PDEC can be adopted. It is surely just a matter of time before this approach is applied more widely throughout the hot dry regions of the world [Fig. 9]

\section{References}

Alvarez, S. (1991). A series of papers including 'Full scale experiments in EXPO '92 The Bioclimatic Rotunda' published in Architecture and Urban Space, Proceedings of the Ninth PLEA Conference, Seville, Spain.

Bahadori, M. N. (1978). 'Passive Cooling Systems in Iranian Architecture' in Scientific American, p.238.

Beazley, E. \& Harverson (1982). Living with the Desert - Working Buildings of the Iranian Plateau, Aris \& Phillips Ltd.

Bunn, R. (2000). TO COME in Building Services Journal.

Cunningham, W. A. and Thompson, T. L. (1986). 'Passive Cooling with natural draft cooling towers in combination with solar chimneys' in PLEA Conference Proceedings, Pecs, Hungary, The Hungarian Society of Sciences.

Fathy, H. (1986). Natural Energy and Vernacular Architecture, University of Chicago Press.

Ford, B., Hewitt, M. (1996). 'Cooling without Air Conditioning - Lessons from India' in arq 1/4, pp.6o-69.

Ford, B., Patel, N., Zaveri, P., Hewitt, M. (1998). 'Cooling without Air Conditioning: The Torrent Research Centre' in the Proceedings of World
Renewable Energy Congress V, Florence, Pergamon.

Ford, B., Diaz, C., Hewitt, M. (200o). 'Passive Downdraught Cooling Architectural Integration in Seville' in the PLEA Conference Proceedings: Architecture, City, Environment, Cambridge, James \& James.

Givoni, B. (1994). Passive and Low Energy Cooling of Buildings, Van Nostrand Reinhold.

Hawken, P., Lovins, A. B., Lovins, L. H. (1999). Natural Capitalism - The Next Industrial Revolution, Earthscan, London, p.134.

Meier, R. and Partners (2001). 'Meier's Green Shift' in Ecotech 3, pp.14-17, Architecture Today.

Von Weisacker, E., Lovins, A. B., Lovins, L. H. (1997). Factor Four - Doubling Wealth-Halving Resource Use, Earthscan, London.

Weston, R. and Ford, B. (1998). Competition entry for the New Constitutional Court, Johannesburg, South Africa unpublished.

\section{Illustration credits}

arq gratefully acknowledges:

Abhikram Architects, 6c

Author, 2, 3a and b, 4b, 6a and b

W. A. Cunningham and T. L. Thomson,

$5^{\mathrm{a}}$
Baruch Givoni, 5b

Hassan Fathy, $1 \mathrm{a}$ and $\mathrm{b}$

Brian Ford Associates, 7a-e and g, 9 Brian Ford Associates with Malcolm Cook of IESD De Montfort

University, $7 \mathrm{f}$

Short Ford Architects, 6d

Richard Weston and Brian Ford, 8

\section{Acknowledgements}

I would like to acknowledge the assistance of my colleagues Camilo Diaz and Rosa Schiano formerly of Brian Ford Associates and now in WSP Environmental for their

contributions to the work described, to Nimish Patel and Parul Zaveri of Abhikram for their collaboration on the Torrent project, and my partners in the PDEC research project which was partially funded by the European Commission.

\section{Biography}

Brian Ford is an architect and environmental design consultant. Formerly a partner in Short Ford Associates, and Professor of Bioclimatic Architecture at De Montfort University, he is currently a consultant and Technical Director with WSP Environmental. 